11. Bashandy M. A. Effect of hunger and thirst stress on the fundic mucosa of the stomach of adult female albino rats. Histological, histochemical and immunohistochemical study. M. A. Bashandy, H. Seleem // J. Am. Sci. 2014. - Vol. 10, № 10. - P. 264-273.

DOI https://doi.org/10.30525/978-9934-26-113-8-28

\title{
HISTO-ULTRASTRUCTURAL CHANGES OF LATERAL GENICULATE BODIES IN COMORBID PATHOLOGY
}

\author{
Shchur M. B. \\ Candidate of Medical Sciences, \\ Doctor-ophthalmolog \\ Municipal Non-Profit Enterprise «City Polyclinic No.2» \\ Lviv, Ukraine
}

Diabetes mellitus (DM) is one of the leading causes of impaired vision and blindness in people aged 20-70 years [6]. The medical and social problem of diabetes is caused by high prevalence, early disability and mortality of patients due to specific complications, one of which is diabetic encephalopathy. According to the scientific literature, diabetic encephalopathy is diagnosed in $80.7 \%$ of patients with type 1 diabetes mellitus (DM) [7]. Research has shown that DM increases the risk of stroke by 2-6 times, transient ischemic attack - by 2-3 times, and in the elderly contributes to the development of chronic cerebral circulation insufficiency (CCCI). CCCI leads to diabetic encephalopathy, accompanied by cognitive impairment and vascular dementia [2]. Therefore, the aim of our study was to establish histo-ultrastructural changes in the lateral geniculate bodies in streptozotocin-induced diabetes (SIDM) under stress.

The study used 15 adult white male rats (body weight 180-200 g), which were equally divided into 3 groups: group 1 - rats with simulated SIDM and immobilization stress, group 2 - rats with SIDM, group 3 - intact animals. In groups 1 and 2 SIDM was simulated by a single intraperitoneal injection of streptozotocin «SIGMA» (USA), which was diluted in $0.1 \mathrm{M}$ citrate buffer with a $\mathrm{pH}$ of 4.5 (at the rate of $6 \mathrm{mg}$ per $100 \mathrm{~g}$ of body weight). In group 1 , SIDM was simulated and starting from the $14^{\text {th }}$ day of the experiment chronic immobilization stress was simulated on a once-only basis by placing the animal in a closed plastic container for 5 hours a day. The material was taken on the $14^{\text {th }}$ day from the beginning of the experiment. Histological, electron microscopic, biochemical and statistical research methods were used. For 
morphometric studies, photographs of histological and semithin sections were used (field of view of the light microscope Leica DM750 was photographed using a digital camera ToupCam 5.2M UHCCD C-Mount Sony). Morphometry was performed using ImageJ version 1.47t. Statistical analysis was carried out using the statistical package Stat.Soft.Inc; Tulsa, OK, USA; Statistica 10.

On the $14^{\text {th }}$ day of the experiment, the level of glucose and glycated hemoglobin in the blood of rats of group 1 was the highest one, compared to group 3, and was $15.34 \pm 2.23 \mathrm{mmol} / \mathrm{l}(\mathrm{p}<0.001)$ and $7.13 \pm 0.79 \%(\mathrm{p}<0.01)$, in group $2-13.74 \pm 2.13 \mathrm{mmol} / \mathrm{l} \quad(\mathrm{p}<0.001)$ and $6.32 \pm 0.51 \% \quad(\mathrm{p}<0.01)$, respectively; in group $3-4.57 \pm 0.56 \mathrm{mmol} / 1$ and $1.89 \pm 0.19 \%$. The level of cortisol in 1-2 experimental groups was probably higher than that of intact rats and was: in group $1-30.12 \pm 2.74 \mathrm{ng} / \mathrm{ml}$, in group $2-18.39 \pm 2.13 \mathrm{ng} / \mathrm{ml}$ (in all cases, $\mathrm{p}<0.01$ ), in intact animals (group 3) $-10.11 \pm 107 \mathrm{ng} / \mathrm{ml}$. Such biochemical changes in groups 1 and 2 indicate the development of decompensated diabetes.

On the $14^{\text {th }}$ day of the experiment, in the lateral geniculate bodies of animals of groups 1-2 an uneven distribution of tigroid bodies in the neuroplasm of neuronal bodies was revealed. They form clusters on the periphery of the perikaryon, while in some places around the nuclei chromatolysis is noted. In animals of group 1, enlarged nuclei are displaced to the periphery of the perikaryon and they are enlightened; small vacuoles are visualized on the periphery of the perikaryon. Microhemovessels are filled with erythrocyte sludges. In animals of groups 1-2 on the background of decreasing numerical density of light neurons the number of pycnomorphic and vacuolated neurons increases.

At the ultrastructural level, in dark neurons of animals of group 1 karyorexis, hyperplasia and expansion of the cisterns of granular endoplasmic reticulum, formation of lysosomes and autophagosomes are noted. In most light neurons of rats of groups 1-2 destructive changes of mitochondria are revealed. Some of them have an enlightened matrix, in others the destruction of the inner shell leads to formation of vacuoles. These changes occur against the background of a violation of the blood-brain barrier. Thus, the lumens of carpillaries are filled with erythrocyte sludges. The most pronounced changes are common in endothelial cells, in the cytoplasm of which there is an increase in the number of pinocytic vesicles and vacuoles, and destructive changes in mitochondria. Astrocytic pedicles are enlarged, they have low electron density with small vacuoles and destructively altered mitochondria.

Such changes in neurons of the central nervous system are interpreted differently by various authors. Some scientists $[1,5]$ indicate that insulin and C-peptide deficiency play the main role in the development of diabetic encephalopathy in type 1 diabetes. Another factor that leads to neuronal 102 
damage in DM is the activation of the polyol pathway of glucose metabolism, which leads to structural changes in neurons due to increased sorbitol and decreased taurine content [4]. However, most researchers believe that one of the main pathogenetic factors in the development of diabetic encephalopathy is diabetic microangiopathy in DM leading to impaired cerebral blood flow [7], which was observed in our study too.

In the myelin nerve fibers of the visual pathway there is a thickening and splitting of the lamellae of the lielin. Axoplasm is enriched by neurofilaments and neurotubules, which may indicate a delay in axonal transport. According to scientific data [3], disorders of carbohydrate metabolism are associated with glycosaminoglycan deficiency, which contributes to rapid degenerativedystrophic changes in peripheral nerves.

Thus, in the lateral geniculate bodies of the rats' brain on the $14^{\text {th }}$ day of SIDM development there is an increase in the numerical density of pycnomorphic and vacuolated neurons due to a decrease in the numerical density of normochromic neurons and the segmental demyelination in myelin nerve fibers of the visual pathway. Such changes were observed against the background of the initial signs of diabetic microangiopathy. Animals of group 1 with comorbid pathology have more pronounced changes which indicate the development of diabetic encephalopathy.

\section{References:}

1. Brismar T. Hyllienmark, Ekberg K., Johansson B. L. Loss of temporal lobe beta power in young adults with type 1 diabetes mellitus. Neuroreport. 2002. Vol. 13. P. 2469-73.

2. Esin R. G., Khairullin I. H., Zyangirova S. T., Isaeva Y. N., Esin O. R. Diabetic encephalopathy: pathogenesis, clinical manifestations, approaches to therapy. Klinitsist. 2012 №3-4. P. 10-16.

3. Khachayants N. Yu. Diabetic polyneuropathy. Uspekhi sovremennogo yestestvoznaniya. 2015. №3. P. 87-92.

4. Malone J.I, Hanna S., Saporta S. et al. (2008). Hyperglycemia not hypoglycemia alters neuronal dendrites and impairs spatial memory. Pediatr Diabetes. 2008. Vol. 9, №6. P. 531-539.

5. Sima A. A. Encephalopathies: the emerging diabetic complications. Acta Diabetol. 2010. Vol. 47, № 4. P. 279-93.

6. Son H. O. Modern approaches to the treatment of diabetic retinopathy. Dosiahnennia biolohiii i medytsyny. 2017. Vol. 30, № 2. P. 75-80.

7. Tumansky V. A., Avramenko Yu. N. Some aspects of the morphogenesis of diabetic encephalopathy. Zaporozhskiy meditsinskiy zhurnal. 2013. Vol. 79, № 4. P. 39-42. 